ledge of the hazards and its application inevitably tends to lag behind.

Furthermore, it is impossible for even the keenest and most active medical officer or physician to be in a position to advise employers authoritatively over more than a fraction of the vast field. Contributions are scattered and references often difficult to ascertain and to trace.

There is thus a great, perhaps even a desperate, need for such a book, and though no book is perfect, it seems that the present volume supplies this need adequately. Although different chapters may appeal to different people, all should read the first chapter, written by Dr. Schilling himself. This gives a clear account of the escapable and inescapable errors in the attempt to assess the effects of occupation on health.

As regards the other chapters, the test of reading a chapter on a subject with which one was totally unfamiliar indicated that the task of making a difficult subject clear to all had been accomplished.

This is an important book and is recommended to all those concerned with the health of the workman.

\section{Anatomy and Physiology for Radiographers}

J. E. BlewetT, M.D., D.M.R., F.F.R.; A. M. RACKOW, B.SC., M.B., D.M.R.E. Pp. viii $+322+$ index, with 22 plates and 133 figures. London: Butterworth. 1960. 37s. $6 d$.

This book is intended for students of diagnostic and therapeutic radiography and describes the essentials of human anatomy and physiology. The emphasis is laid on anatomy of bones, joints and muscles, to which almost half of the book is devoted. The therapy students will appreciate especially the chapter on the lymphatic system, which no other book of this size attempts to deal with. Main common diseases appertaining to each system are given at the end of respective chapters and their pathology is briefly explained. The volume is adequately supplied with clearly labelled diagrams and all X-ray plates are accompanied by line drawings. Specialized radiographic techniques are described and the use of contrast media is discussed.

The student will find this book helpful in her studies and interesting in improving her understanding of medical conditions she is dealing with.

\section{Padiatric Pathology}

Daniel Stowens, M.D. Pp. xiii +676 , illustrated. Baltimore: Williams and Wilkins Co. Distributed in Great Britain by Baillière, Tindall \& Cox. r959. I60s.

A comprehensive reference book on pædiatric pathology has been needed for a long time, as pathological criteria of adult pathology are not always applicable to children.

This gap has now been largely filled by the publication of this book. This is a very comprehensive volume covering such diverse aspects as diseases of the placenta, poisoning, experimental teratology, inborn errors of metabolism and sudden deaths in infancy, as well as the usual systematic pathology. A very useful section on normal weights and sizes at various stages of development is included. This is invaluable when trying to assess maturity or abnormality.
Perhaps this very comprehensiveness is one of it main weaknesses; because the author has aimed to coves the whole field the book is often tantalizingly brief on individual topics. It tends to skim over the surface of many problems rather than deal with them in detail $\Rightarrow$. To make up for this to some extent there are good lists? of references at the end of chapters. However, on sometimes misses the insertion of these references into the text.

On the whole the book is well written and it is beautifully and profusely illustrated, unfortunately with photomicrographs only. Sometimes, however, the pictures are unnecessarily large, taking up the wholes page without adding anything useful, and one feels that without this extravagance the book might have beenproduced at a lower cost. An appendix is included which $\vec{\varpi}$ gives the details of the enormous material upon which the preparation of this book was based.

In spite of the defects mentioned, this is a book which should be on the reference shelf of every pathologist. who is called upon to deal with pædiatric morbid anatomical problems.

\section{Cancer of the Breast}

Compiled and Edited by Willard H. Parsons. Pp. xv + 232, illustrated. Blackwell Scientific Publications. 1960. 60s.

This book was designed to give a concise presentationof the more important and controversial aspects of breasto cancer. The text is alive, and seems to present the? working knowledge and reasoned observations of meno with much experience, and a lively interest in their subject. References to the literature are abundaot, $\overrightarrow{0}$ and point the path by which present-day conceptionso have been reached, but there is no routine repetition 7 f standard description. The account of surgical patholot is notably fresh and vivid. The classification of types of breast cancer is full enough to satisfy the academician, but the reader is constantly reminded of the commono varieties which he will meet in day-to-day practice. Clinical examination, diagnosis and prognosis are welli described, with a fair account of conflicting views, for example upon the value of histological grading.

The preparation and post-operative care are fully discussed with valuable guidance in the management of patients who have been receiving steroids or hypotensive drugs. The comments on anæsthesia are rather naive'the fact that endotracheal anæsthesia makes a poor anæsthetist look good is scarcely sufficient cause to use. it in radical mastectomy ${ }^{-}$. Operative technique of the radical operation is given a standard description, not notably helpful.

The value of simple mastectomy and irradiation, and of superradical operation, is fairly discussed. Hormonal therapy is not very well presented.

The story of Huggins' pioneer work on adrenalectomy is not told, and hypophysectomy is dismissed in nineo lines as awaiting further trial: this is scarcely adequate treatment in a book published in 1959.

This is a book which teaches surgery as it should be taught, giving a sketch of history, based on facts from $\mathrm{N}$ published work, and a sane review of conflicting opinions $N$ by authors of wide experience, widely read. It is a pity there are not more like it. It can be recommended to the postgre luate student. 